\title{
"Plantar pro gasto": a importância do autoconsumo entre famílias de agricultores do Rio Grande do Sul'
}

Catia Grisa ${ }^{2}$

Sergio Schneider ${ }^{3}$

Resumo: O artigo discute a valoração e importância da produção para o autoconsumo na reprodução social das unidades familiares e caracteriza os alimentos autoconsumidos. Vale-se da pesquisa "Agricultura Familiar, Desenvolvimento Local e Pluriatividade” (UFRGS/UFPel/ CNPq-2003) que propiciou a formação de um banco de dados com informações sobre a dinâmica da agricultura familiar em quatro regiões distintas da geografia gaúcha, suas fontes e tipos de renda, entre estas o autoconsumo. Trazer este debate significa retomar um tema pouco discutido até então, e que, embora marginalizado ou considerado sem importância, desenvolve importante papel como renda não monetária, fortalece a segurança alimentar e adentra esferas da sociabilidade e

${ }^{1}$ Este artigo é fruto de recente dissertação de mestrado defendida junto ao Programa de Pós-Graduação em Desenvolvimento Rural - Grisa (2007), a qual recebeu o Prêmio SOBER 2007 de Melhor Dissertação em Extensão e Sociologia Rural.

${ }^{2}$ Engenheira agrônoma. Mestre em Desenvolvimento Rural (PGDR/UFRGS). Doutoranda no Programa de Pós-Graduação de Ciências Sociais em Desenvolvimento, Agricultura e Sociedade (CPDA/UFRRJ). E-mail: catiagrisa@yahoo.com.br Av. N. S. de Fátima 64, Ap 401, Centro, Rio de Janeiro, CEP: 20240.051. A autora agradece a CAPES pelo apoio no desenvolvimento desta pesquisa.

${ }^{3}$ Sociólogo. Mestre e Doutor em Sociologia. Professor do Programa de Pós-Graduação em Desenvolvimento Rural e Programa de Pós-Graduação em Sociologia da Universidade Federal do Rio Grande do Sul. Pesquisador do CNPq (Bolsa Produtividade). Email: schneide@ufrgs.br Universidade Federal do Rio Grande do Sul, Programa de Pós Graduação em Desenvolvimento Rural. Av. João Pessoa, 31. Porto Alegre -RS. CEP: 9004.000 
identidade social. Além da introdução, apresenta-se o papel do autoconsumo na agricultura familiar, o cálculo da produção para o autoconsumo, discussão dos objetivos e resultados, e considerações finais. Os resultados demonstram que a produção para o autoconsumo é uma estratégia recorrente pelas unidades familiares e se diferencia de acordo com a dinâmica da agricultura familiar. Diferença esta expressa em valores relativos (\%) e no número de estabelecimentos pertencentes a estratos diferenciados de autoconsumo, e pouco nos tipos de alimentos produzidos para este fim, observando-se uma homogeneidade dos hábitos alimentares.

Palavras chaves: agricultura familiar, autoconsumo, reprodução social.

Abastract: The article discusses the value and importance of the selfconsumption production in the social reproduction of the family units and it characterizes the food self-consumed. The paper used the research "Family Farm, Local Development and Pluriactivity" (UFRGS/ UFPel/CNPq-2003) that propitiated the formation of a database with information on the dynamics of the family farm in four areas different from the geography of the Rio Grande do Sul, your sources and types of income, among these the self-consumption. To bring this debate means to retake a theme little discussed until then, and that, although marginalized or considered without importance, it develops important role as income non monetary, strengthens the food security and it penetrates spheres of the sociability and social identity. Besides the introduction, is presented the role of the self-consumption in the family farm, the calculation of the self-consumption production, discussion of the objectives and results, and final considerations. The results demonstrate that the self-consumption production is an appealing strategy for the family units and it differs in agreement with the dynamics of the family farm. It differentiates this expresses in relative values (\%) and in the number of establishments belonging to differentiated strata of self-consumption, and a little in the types of foods produced for this end, being observed a homogeneity of the alimentary habits. 
Key words: family farm, self-consumption, social reproduction.

JEL Classification: Q18, R31 e R32

\section{Introdução}

A agricultura e o meio rural da região Sul do Brasil passaram por profundas transformações desde a década de 1970. Elementos característicos da "pequena agricultura" ou da agricultura camponesa foram sendo substituídos por novas práticas e meios de produção. Assim aconteceu com a enxada, a tração animal, a carroça, a colheita manual, entre outros, que são agora utilizados com pouca intensidade e encontrados esporadicamente. Seguindo esta tendência, chegou-se a presumir que outras características da agricultura e do meio rural também seriam alteradas, como a produção para o autoconsumo. Acreditando na inexorabilidade deste processo, muitos estudiosos passaram a considerar a produção para o autoconsumo como algo sem futuro, que se tornaria residual e perderia sua importância à medida que a modernização da agricultura se consolidasse. Não sem motivo, este tema foi relegado a plano secundário, quase ignorado pelos estudiosos, o que reflete o pouco conhecimento existente atualmente.

No entanto, o autoconsumo permanece uma estratégia recorrente entre os agricultores familiares e reveste-se de fundamental importância para a reprodução social destas unidades. O que este trabalho pretende demonstrar é que a manutenção da produção para autoconsumo entre os agricultores não é decorrente de sua teimosia e nem de sua infinita capacidade de se submeter a condições de trabalho e produção pouco aceitáveis. Pretende-se demonstrar que esta atividade faz parte de um modo de organizar a atividade produtiva e reflete um repertório cultural que caracteriza a sociabilidade e identidade destes agricultores. Ao se retomar este tema, pretende-se contribuir para desmistificar o preconceito existente em relação à produção para autoconsumo e mostrar sua relevância como fonte de renda não-monetária, que efetivamente auxilia na melhoria das condições de vida, na segurança alimentar e no combate à pobreza rural.

O ponto de partida deste estudo relaciona-se com os trabalhos e 
estudos sobre a dinâmica da agricultura familiar no Rio Grande do Sul. As pesquisas iniciadas a partir do projeto "Agricultura Familiar, Desenvolvimento Local e Pluriatividade” (AFDLP - UFRGS/UFPel/ CNPq-2003) demonstraram, em distintas regiões do estado, como os agricultores familiares desenvolvem diferenciadas estratégias de reprodução que se assentam em um amplo leque de atividades e ações, desde àquelas ligadas à produção agrícola strictu senso, passando pela pluriatividade, recorrendo aos benefícios da previdência social, ou acionando relações interpessoais através de redes de reciprocidade. ${ }^{4}$ Tal como demonstrado por Gazolla (2004), a produção para o autoconsumo integra este portfolio de estratégias e ações, sendo presente e importante mesmo em contextos extremamente mercantilizados, como a região do Alto Uruguai.

De certa forma, já existem conhecimentos e resultados importantes sobre a produção para autoconsumo. Já se sabe, por exemplo, a relevância como instrumento para reduzir a vulnerabilidade e insegurança alimentar das famílias, o que contribui para minimizar a pobreza no meio rural (GAZOLLA, 2004). Contudo, para sair do âmbito dos estudos de caso, considera-se que o tema precisa romper a barreira e deixar de ser visto como uma particularidade ou especificidade. Os passo iniciais nesta direção foram dados a partir dos estudos comparativos de Anjos et al.(2004) e Peyré Tartaruga (2005), que examinaram de forma preliminar a expressão da produção para o autoconsumo em distintas regiões do Rio Grande do Sul.

Este trabalho pretende dar continuidade a estes estudos comparativos desenvolvidos no âmbito do Grupo de Estudos e Pesquisas em Agricultura Familiar e Desenvolvimento Rural $\left(\mathrm{GEPA}_{\mathrm{f}} \mathrm{D}_{\mathrm{r}}\right.$, assumindo como objetivos: demonstrar a importância da produção para ao autoconsumo em contextos distintos, valorar o autoconsumo em quatro municípios pesquisados e, caracterizar os alimentos autoconsumidos em cada um deles.

O artigo está estruturado em quatro partes, além desta introdução. A primeira está dedicada a uma revisão da literatura sobre o tema. Procura-se apresentar como a produção para o autoconsumo é interpre-

${ }^{4}$ Destacam-se Conterato (2004), Radomsky (2006), Schneider et al. (2006) e Niederle (2007), entre outros. 
tada nos estudos sobre organização econômica e produtiva dos camponeses e agricultores familiares, e discutir os papéis que desempenha. A segunda seção expõe a metodologia utilizada na pesquisa e mostra como se procedeu a mensuração da produção para o autoconsumo. Na terceira discutem-se os principais resultados e analisam-se de forma comparativa os dados num universo amostral que representou quatro municípios de diferentes regiões do estado. Na última seção apresentam-se as conclusões do trabalho.

\section{O autoconsumo na agricultura familiar: elementos para o debate}

A produção para o autoconsumo, também denominada mínimo calórico, mínimo alimentar vital, consumo doméstico e, popularmente, produção "pro gasto", é definida como a parcela da produção produzida pela família e destinada ao seu consumo. É equivoco estereotipar esta produção como residual, ou ainda associar a quantidades pequenas e produtos incompatíveis com os padrões de qualidade dos mercados. $\mathrm{O}$ que a caracteriza é o seu valor de uso para os membros da família.

Ainda no âmbito das conceituações, este trabalho assume que produção para o autoconsumo e produção para subsistência não são sinônimos, como corriqueiramente é utilizado. De acordo com Garcia Jr. (1983, p. 16), os camponeses organizam a unidade familiar visando fundamentalmente atender sua subsistência, isto é, “(...) aquilo que é socialmente necessário para a reprodução física e social do trabalhador e de sua família”. Para tanto, os camponeses cultivam vários produtos nos roçados, hortas e pomares, mantém a produção de animais domésticos e, em alguns casos, utilizam-se da caça, pesca e coleta. Uma parte dos alimentos obtidos é destinada ao autoconsumo, outra às relações de trocas onde se adquirem outros bens necessários. Destarte, produção para a subsistência é mais ampla que autoconsumo. Enquanto este pressupõe somente o que é consumido pela família, aquela envolve ainda a produção destinada à circulação mercantil, a partir da qual são adquiridos recursos igualmente importantes para a reprodução social.

O termo produção de subsistência é equivalente à expressão 
"produção para aprovisionamento" utilizada por Sahlins, que afirma: “(...) a produção doméstica não é descrita exatamente como produção para uso, isto é, para o consumo direto. As famílias também podem produzir para troca, assim conseguindo indiretamente o que precisam" (SAHLINS, 1970, p. 118, grifos no original). Igualmente, Woortmann (1978, p. 05) sustenta que “(...) é apenas em parte que a reprodução da força de trabalho camponesa se realiza pelo autoconsumo; com a comercialização de seus produtos o camponês apura uma renda monetária indispensável à sua subsistência, inclusive para a compra de alimentos".

O tema da produção para o autoconsumo nas ciências sociais foi particularmente intenso entre antropólogos, etnógrafos e sociólogos que estudavam o campesinato. Destacam-se sobretudo as contribuições de Chayanov (1974) e Wolf (1976) que, não obstante as distintas perspectivas, evidenciam o autoconsumo como uma importante dimensão na organização produtiva e econômica dos camponeses, quando não a principal (no caso da tese de Chayanov).

Alguns estudos brasileiros também se dedicaram à temática, igualmente perseguindo entender a organização das unidades camponesas (HERÉDIA, 1979; GARCIA JR. 1983,1989; WOORTMANN e WOORTMANN, 1997; CÂNDIDO, 2001). Para estes, os camponeses organizam a unidade familiar e produtiva de modo a atender a sua subsistência. Os camponeses cultivam várias espécies de alimentos - mantém a horta, a produção de frutas, a lavoura, a produção de animais domésticos - caçam, pescam e ainda utilizam-se quando necessário de formas complementares à subsistência (a venda da força de trabalho, por exemplo). Neste escopo, o autoconsumo desenha-se uma estratégia central para a reprodução social dos camponeses.

Embora a produção para o consumo familiar atenda em grande medida as necessidades alimentares, há alimentos que não podem ser produzidos pela família e que são indispensáveis. O atendimento destas e de outras necessidades demanda que a família estabeleça relações com os mercados através da comercialização de parte da produção. Para contemplar estas duas esferas, consumo e venda, a preferência de cultivar recai sobre os produtos que apresentam a marca da "alternatividade” que, de acordo com Herédia (1979) e Garcia Jr. (1983), possibi- 
litam tanto ser consumidos quanto vendidos. Faz parte das estratégias dos camponeses aproveitarem esta característica em situações de preços favoráveis ou tratando-se de alimentos perecíveis. Prefere-se os cultivos que apresentem esta marca (também denominados "lavouras de subsistência”) vis-à-vis às "lavouras comerciais”, em virtude de a primeira garantir diretamente o consumo familiar e/ou a venda, enquanto na segunda, o acesso aos alimentos fica mediado exclusivamente pela realização da venda e a posterior compra, onde há o risco de flutuações de preço e ainda este não ser compensador (GARCIA JR., 1983).

As principais variáveis a influenciar esta organização produtiva e econômica dos camponeses e, por conseguinte, também o autoconsumo, são o número e a composição da unidade familiar. Estas refletem o consumo socialmente necessário e a disponibilidade de força de trabalho do grupo familiar, resultando no "balanço entre trabalho e consumo”, especificado por Chayanov (1974), ou seja, a quantidade de trabalho empregada é determinada pelas necessidades de consumo da família. É a partir desta equação que se opta por um ou por outro cultivo, e ainda produzir ou comprar, autoconsumir ou vender determinado produto.

Contudo, esta relação entre autoconsumo e campesinato, e a própria organização produtiva e econômica como um todo dos camponeses, vai sendo alterada à medida que ocorre a inserção das unidades familiares aos mercados e a penetração das relações capitalistas no campo. Cresce uma nova lógica organizativa mediada pelo mundo das mercadorias. O camponês não aspira mais somente atender a sua subsistência, mas fazendo parte da sociedade moderna deseja o acesso a um conjunto de bens materiais e culturais. Como demonstrou Cândido (2001, p. 207), ao mesmo tempo em que se transforma em um produtor de mercadorias também se torna um consumidor destas.

Surgem assim (...) necessidades novas, que contribuem para criar ou intensificar os vínculos com a vida das cidades, destruindo sua autonomia e ligando-o estritamente ao ritmo da economia geral, isto é, da região, do estado e do país, em contraste com a economia particular, centralizada pela vida de bairro e baseada na subsistência. Doravante, 
ele compra cada vez mais, desde a roupa e os utensílios até alimentos e bugigangas de vário tipo; em conseqüência, precisa vender cada vez mais. (CÂNDIDO, 2001, p. 207)

Neste contexto, as unidades familiares intensificam o ritmo de trabalho, dão preferência aos “cultivos comerciais”, independente do princípio da alternatividade, e especializam-se em poucas culturas, diferentemente da policultura existente outrora. A produção para o autoconsumo passa de uma condição prioritária para complementar. $\mathrm{O}$ tempo de trabalho, a mão-de-obra disponível e os recursos produtivos são reorganizados em função dos cultivos comerciais e estes disputam espaço com o autoconsumo, condicionando-o a uma função de complementaridade. Além disso, a facilidade e a disponibilidade variada de alimentos nos mercados (inclusive de alimentos fora da estação) são fatores que potencializam esta reorganização da unidade familiar. Este mesmo processo que altera o lugar do autoconsumo na organização produtiva e econômica dos camponeses, também, segundo Abramovay (1998, p. 126), "metamorfoseia” os camponeses em agricultores familiares, e "(...) aquilo que era antes de tudo um modo de vida converte-se numa profissão, numa forma de trabalho.”

Embora a condição de complementaridade dentro da unidade de produção, o autoconsumo continua sendo uma estratégia recorrida pela grande maioria das explorações familiares e cumpre papéis importantes na agricultura familiar. Dentre as várias motivações para a sua existência, provavelmente a mais assídua situe-se no aspecto econômico por tratar-se de uma forma de “economização”, como denominou Lovisolo (1989). Ou seja, ao produzir seus próprios alimentos, a unidade familiar deixa de gastar o equivalente em recursos monetários com a compra de alimentos nos supermercados. Similarmente, Woortmann (1978, p.114) argumenta que “(...) realizando seu consumo alimentar em boa medida pela produção própria, o pequeno lavrador aumenta as possibilidades de realização, pela via do mercado, de outras fontes de consumo, não menos importantes para sua reprodução como ser social”.

A relevância do autoconsumo para a segurança alimentar, como bem discutiu Gazolla (2004), pode ser outro fator. A produção para o autoconsumo permite acesso facilitado, sem nenhum processo de inter- 
mediação por meio de valores de troca, a um conjunto diversificado de alimentos capazes de fornecer os mais diversos nutrientes que o organismo humano necessita. Também, o autoconsumo é uma forma de produção que respeita as preferências alimentares das comunidades locais, suas práticas de preparo e consumo, e serve como um instrumento de preservação da cultura, dada que muitas destas práticas são passadas de pais para filhos, em consonância com as condições sócioambientais e a própria história local. Ademais, fornece alimentos com qualidade sanitária, dado que comumente trata-se de cultivos isentos de agrotóxicos e insumos químicos. Os alimentos comprados parecem não ser confiáveis quanto a estes critérios, mesmo adotando medidas profiláticas. Assim, como observou Gazolla (2004), pode-se afirmar que o autoconsumo atende a vários princípios da segurança alimentar definidos pelo CONSEA (2004).

Em seu magistral estudo sobre os caipiras do Rio Bonito, Cândido (2001) observa que a alimentação é "fulcro de sociabilidade”, e o mesmo pode ser estendido para a produção para o autoconsumo. Na medida em que possui valor de uso para os agricultores, geralmente serve para manter e fortalecer relações sociais com a família e vizinhança. É comum entre vizinhos e membros da comunidade a troca de produtos da horta, sementes, frutas, produtos que nos vizinhos ainda não estejam em fase de colheita, entre outros. Esta produção também está presente nas visitas, nos "filós” típicos da cultura italiana, encontros, reuniões e festas. Mais que alimentar necessidades vitais, nestes casos, a produção para o autoconsumo alimenta sociabilidades, firma relações entre vizinhos, estabelece compromissos, consolida a vida comunitária e uma estrutura social importante para reprodução social das unidades familiares.

Destaca-se, por fim, a importância do autoconsumo para demarcar a identidade do agricultor e de sua família. Segundo Woortmann e Woortmann (1997), garantir a satisfação alimentar do grupo familiar com a mínima dependência externa significa que o pai e a mãe desempenharam com sucesso suas funções. Outrossim, Brandão (1981, p. 79, grifos no original) observa que "Há um certo orgulho entre casais de lavradores e camponeses em provar que quase tudo o que a família usa e consome é obtido ali mesmo e como resultado do trabalho da família 
sobre a terra”. Deste modo, a autonomia alimentar ou a garantia de satisfação das necessidades alimentares por meio da própria produção de alimentos confere legitimidade à família perante as demais. Ao produzir para o autoconsumo as unidades familiares se auto-reconhecem e são reconhecidas.

É o conjunto destas motivações que levam as unidades familiares a produzirem para o autoconsumo, e são estas também que justificam a necessidade das ciências sociais retomarem este tema de estudo que apresenta várias lacunas a ser preenchidas com teoria social e pesquisa empírica. Não se trata de uma estratégia arcaica ou sem importância, ela faz parte dos meios de vida encontráveis no espaço rural contemporâneo e pode se tornar um mecanismo que contribui para o seu desenvolvimento.

\section{A metodologia da pesquisa e o cálculo da produção para o autoconsumo}

Com mencionado anteriormente este trabalho insere-se no projeto de pesquisa "Agricultura Familiar, Desenvolvimento Local e Pluriatividade: e emergência de uma nova ruralidade no Rio Grande do Sul" (AFDLP - UFRGS/UFPel/CNPq-2003). Esta pesquisa foi desenvolvida em quatro regiões - a Serra Gaúcha, a Serra do Sudeste, as Missões e o Alto Uruguai - visando captar a diversidade social, econômica, cultural e geográfica da agricultura familiar gaúcha. Em cada uma destas regiões foi escolhido um município que melhor representasse as características regionais, onde seriam coletados os dados da pesquisa. Foram escolhidos: Veranópolis, Morro Redondo, Salvador das Missões e Três Palmeiras, pertencentes respectivamente às regiões citadas. Na Figura 01 observa- se a localização destas regiões e municípios na geografia do Rio Grande do Sul.

De modo breve pode-se caracterizar Veranópolis como um município que apresenta uma dinâmica de desenvolvimento endógeno. A economia é diversificada, arraigada na agricultura, na indústria, comércio e turismo, e encontra no próprio ambiente local os recursos (humanos, naturais, capital etc.) para sua reprodução. Morro Redondo apresenta uma economia dependente do setor agroindustrial que passa por longa 
crise desde a abertura do mercado brasileiro às importações na década 1990. Por conseguinte, a agricultura oferece poucas perspectivas e fora deste universo também há escassas alternativas. Salvador das Missões e Três Palmeiras apresentam uma dinâmica de desenvolvimento concentrada nas atividades agrícolas, e aqui sobretudo no binômio trigo-soja, herança da modernização da agricultura. Em Salvador das Missões, a diversificação produtiva vem sendo resgatada em anos recentes. Em Três Palmeiras, a pobreza acentuada e a desigualdade de renda e riqueza intensificam e são intensificadas pela vulnerabilidade advinda do modelo de desenvolvimento produtivista perseguido.

Figura 01 - Localização das microrregiões e municípios estudados no Rio Grande do Sul e Brasil.

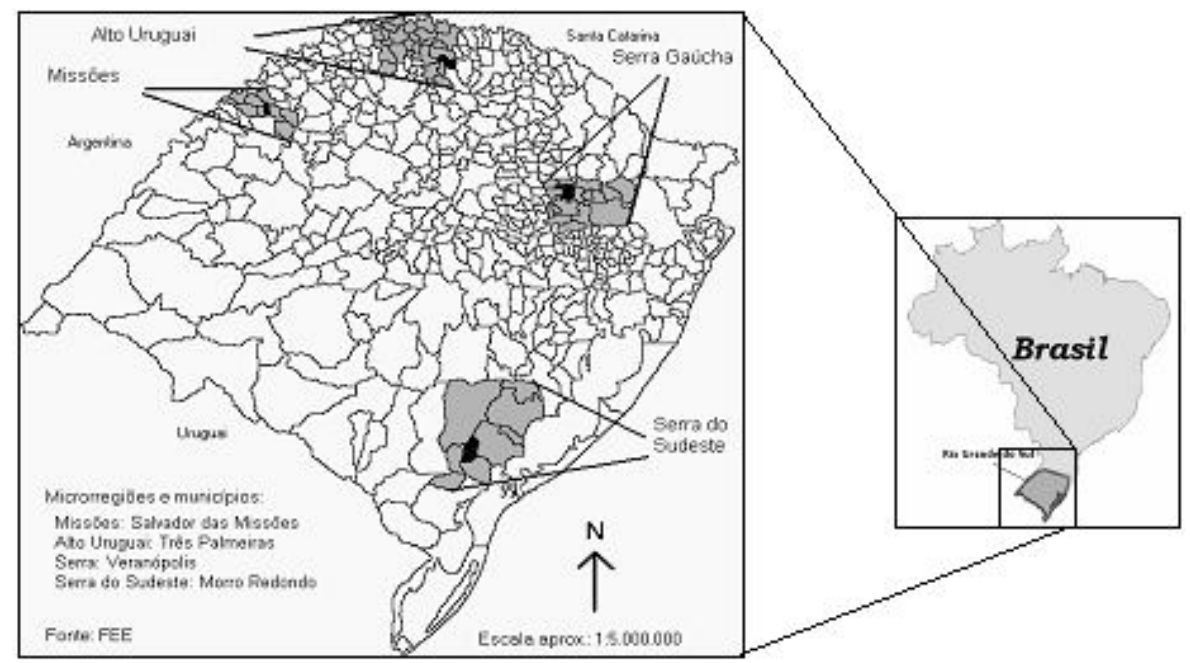

Fonte: Fundação De Economia E Estatística Siegfried Emanuel Heuser - FEE, 2006.

Com o propósito de tornar mais visível ao leitor algumas das diferenças socioeconômicas entre os municípios abordados nesta pesquisa, apresenta-se a Tabela 01. Pode-se observar que, entre os universos sociais estudados, Veranópolis é aquele que apresenta o maior índice de Índice de Desenvolvimento Humano $\left(\mathrm{IDH}^{5}\right),(0,85)$, e igualmente os ${ }^{5} \mathrm{O}$ Índice de Desenvolvimento Humano (IDH), composto por três componentes: longevidade, educação e renda, varia de 0 a 1 , sendo que quanto mais próximo do primeiro pior a condição de desenvolvimento humano, e quanto mais próximo de 1, melhor. 
maiores valores de renda agrícola $(\mathrm{R} \$ 14.853,28)$ e total $(\mathrm{R} \$ 26.969,50)$. Também é aquele com o mais elevado número de famílias exercendo atividades não-agrícolas $(59,32 \%)$, o que é fruto da diversidade e dinamismo econômico presente nesta localidade. No oposto das condições socioeconômicas, estão Morro Redondo e Três Palmeiras alternando posições. Enquanto Três Palmeiras apresenta o menor índice de IDH $(0,76)$ e a menor renda total $(\mathrm{R} \$ 11.033,12)$, Morro Redondo é aquele com a menor renda agrícola ( $\mathrm{R} \$ 6.610,55)$ e onde a renda da previdência social assume maior importância relativa $(25,89 \%)$, fruto das escassas possibilidades de diversificação. É nestes dois municípios que a vulnerabilidade social é mais acentuada vis-à-vis os demais. Salvador das Missões possui índices semelhantes aos de Veranópolis, e intermediários entre todos os municípios pesquisados, como, por exemplo, no concerne, respectivamente, ao IDH $(0,81)$ e a renda total $(\mathrm{R} \$ 18.911,28)$. Destaca-se ainda, elucidando o caráter eminentemente agrícola de Salvador das Missões e Três Palmeiras, a porcentagem do VAB agropecuário sobre o VAB total, cujos valores são respectivamente, 54,69\% e 65,53\%.

No âmbito da pesquisa AFDLP (2003) foram aplicados 59 questionários estruturados em Veranópolis, 62 em Morro Redondo, 58 em Salvador das Missões e 59 em Três Palmeiras, perfazendo um total de 238 questionários. Atingiu-se aproximadamente 10\% dos estabelecimentos familiares de cada município. A escolha dos estabelecimentos ocorreu segundo o método de amostragem sistemática por comunidade, garantindo a representatividade na pesquisa de cada uma das comunidades dos municípios, o que não seria alcançado utilizando o método sistemático por município. Assim, o sorteio não ocorreu para toda a amostra, mas para cada comunidade, e o intervalo sistemático válido refere-se a este universo, diferindo conforme seu tamanho. Estes questionários geraram um banco de dados analisado por meio dos softwares SPSS (Statistical Package for Social Sciencies) e EXCELL.

Em 2006 procedeu-se à realização de 35 entrevistas semi-estruturadas, distribuídas entre os municípios. A amostragem dos estabelecimentos ocorreu agora de modo intencional, visando contemplar a diversidade da produção para o autoconsumo em termos de valores monetários anuais entre os estabelecimentos familiares. Ao longo deste trabalho, fragmentos dos discursos gravados são transcritos ipsis 
verbis, sendo as entrevistas identificadas pela letra "I" de informante, por um número (ordem em que foram realizadas) e pelas iniciais do nome do município (e.g. I 05, SM). Além dos questionários e entrevistas, também se utilizaram dados de fontes secundárias (IBGE, FEE, entre outros).

Tabela 01: IDH-M, População Total, População Rural, VAB Total em reais $(\mathrm{R} \$)$ e outros indicadores referentes aos universos pesquisados.

\begin{tabular}{|c|c|c|c|c|}
\hline Indicadores & Veranópolis & $\begin{array}{c}\text { Morro } \\
\text { Redondo }\end{array}$ & $\begin{array}{c}\text { Salvador } \\
\text { das Missões }\end{array}$ & $\begin{array}{c}\text { Três } \\
\text { Palmeiras }\end{array}$ \\
\hline IDH - M (2000) & 0,85 & 0,77 & 0,81 & 0,76 \\
\hline População Total (2005) & 21.114 & 5.906 & 2.403 & 4.229 \\
\hline $\begin{array}{l}\text { Porcentagem População Rural } \\
\text { (2005) }\end{array}$ & 14,59 & 58,69 & 62,88 & 57,25 \\
\hline VAB Total em mil R\$ (2003) & $401.875,00$ & $52.282,00$ & $52.543,00$ & $49.396,00$ \\
\hline $\begin{array}{l}\text { Porcentagem VAB } \\
\text { Agropecuária (2003) }\end{array}$ & 10,80 & 29,81 & 54,69 & 65,53 \\
\hline PIB per capita em R\$ (2003) & $20.776,00$ & $9.454,00$ & $20.297,00$ & $11.016,00$ \\
\hline $\begin{array}{l}\text { Área média dos } \\
\text { estabelecimentos }\end{array}$ & 23,19 & 22,79 & 14,11 & 19,66 \\
\hline Renda Total em $\mathrm{R} \$$ * & $26.969,50$ & $12.914,83$ & $18.911,28$ & $11.033,12$ \\
\hline Renda Agrícola em R \$ * & $14.853,28$ & $6.610,55$ & $12.047,52$ & $8.081,40$ \\
\hline $\begin{array}{l}\text { Renda Atividades Não- } \\
\text { agrícolas em } \% * *\end{array}$ & 20,83 & 18,11 & 17,15 & 6,55 \\
\hline $\begin{array}{l}\text { Porcentagem de famílias } \\
\text { pluriativas }\end{array}$ & 59,32 & 41,94 & 46,55 & 28,81 \\
\hline $\begin{array}{l}\text { Renda Transferências Sociais } \\
\text { em } \% * *\end{array}$ & 19,90 & 25,89 & 15,64 & 15,10 \\
\hline $\begin{array}{l}\mathrm{N}^{\circ} \text { médio de pessoas por } \\
\text { família }\end{array}$ & 4,59 & 3,87 & 4,45 & 4,02 \\
\hline
\end{tabular}

Fonte: Programa Das Nações Unidas Para O Desenvolvimento - PNUD et al., 2000; Instituto Brasileiro De Geografia E Estatística - IBGE, 1998; FEE, 2006; Pesquisa AFDLP - UFRGS/UFPel/CNPq (2003).

* Valores médios por estabelecimento.

** Proporção sobre a renda total

É mister discutir também a metodologia referente ao cálculo da produção para o autoconsumo, uma das questões de maior dificuldade ao se estudar a temática. O que considerar como produção para o autoconsumo? Como levantar os dados da produção autoconsumida? Que 
"Plantar pro gasto": a importância do autoconsumo entre famílias de agricultores do Rio Grande do Sul

valor atribuir a esses produtos? Estas são algumas das questões metodológicas que permeiam o cálculo do autoconsumo. Talvez esta seja uma das razões que contribui para afastar pesquisadores do tema ou para outros acreditarem que poderia se tratar de uma produção marginal.

Diferentemente de autores como Leite (2004), Garcia Filho (1999) e Lovisolo (1989) que consideram autoconsumo a produção destinada à alimentação da família, dos animais e ainda a construção de objetos de uso da família (ferramentas, roupas, lenha etc.), neste trabalho entende-se por produção para o autoconsumo a parcela da produção animal, vegetal e transformação caseira ${ }^{6}$ produzida pela unidade familiar e destinada ao seu consumo. Estas diferenças decorrem dos distintos recortes metodológicos particularizados em cada pesquisa.

O levantamento dos produtos autoconsumidos ocorreu através de questionários que discriminavam o consumo anual, diferenciados quanto à origem animal e vegetal. ${ }^{7}$ Quanto aos alimentos da horta e do pomar, foi solicitado aos entrevistados que estimassem o consumo em valores monetários (e não o detalhamento) em decorrência da grande variabilidade destes produtos e da dificuldade de conseguir contabilizar as quantidades consumidas em um ano agrícola (quantos pés de alface, laranjas, tempero verde etc.).

O valor atribuído a esses alimentos foi estimado com base no preço ao produtor (preço de venda). Esta opção vai de encontro à metodologia adotada por Garcia Jr. (1989) que considera os preços ao consumidor (de compra). A escolha de Garcia Jr. deve ser interpretada juntamente com sua obra, cujo objetivo era comprovar que inseridos numa dinâmica capitalista, os camponeses também eram guiados por uma racionalidade econômica. Se os preços destes fossem de tal ordem que produzindo lavouras comerciais, com o mesmo trabalho despendido, pudessem fazer frente às demandas alimentares da família, a opção seria pela produção comercial e

${ }^{6}$ Os valores da transformação caseira não foram contabilizados no produto bruto do autoconsumo total em virtude do questionário não permitir a separar a matéria-prima consumida diretamente pela família daquela utilizada para a produção de derivados. Esta é uma questão difícil até mesmo para as unidades familiares, que raramente contabilizam seus gastos.

${ }^{7}$ As quantidades de cada produto foram uniformizadas em termos de unidade de medida e quando o entrevistado não soube informar o preço de venda utilizou-se o recurso da estimação deste a partir da média geral informada pelos demais entrevistados para o mesmo produto no município pesquisado. 
não pelo autoconsumo. Por lançar mão deste calculo é que a produção para o autoconsumo teria que ser balizada pelo preço ao consumidor, evidenciando o quanto a família gastaria comprando os alimentos necessários.

A grande variação de preços ao consumidor entre mercados é uma das razões que justifica a opção pelo preço de venda, como explicitaram Anjos et al. (2004). Disparidade que se potencializa quando se tratam de municípios distintos e distantes geograficamente, como é caso nesta pesquisa. Ademais, a pesquisa a qual se insere este trabalho tinha como objetivo identificar as diferentes fontes de renda das unidades familiares e, deste modo, se utilizado o preço de compra estar-se-ia superestimando a proporção do autoconsumo sobre e a própria renda total das famílias rurais.

Cabe considerar que são limitadas as possibilidades de se obter os valores monetários líquidos da produção para o autoconsumo. Isto porque, como afirma Gazolla (2004), há dificuldades para se isolar, de forma exata, as despesas que incorrem sobre esta produção daquelas destinadas à venda. Por exemplo, são remotas as possibilidades de conseguir separar o custo da energia elétrica utilizada na ordenha das vacas, cujo leite parte vai para a venda e parte para o consumo, daquela do consumo geral da família. Sendo assim, prefere-se calcular o autoconsumo na forma de produto bruto (valor bruto) e não produção líquida.

Finalmente, em relação ao cálculo da produção para o autoconsumo, é mister advertir, como já recomendava Chayanov (1981), que as unidades econômicas camponesas não podem ser analisadas e tratadas a partir dos conceitos e princípios utilizados para medir a eficiência de uma empresa capitalista. Isto se deve, segundo o autor, ao fato dos agricultores (para ele, camponeses, todavia, o mesmo pode ser aplicado aos agricultores familiares) organizarem seu trabalho e sua produção não com a finalidade de obter lucro, mas, sobretudo, de atender o bemestar de sua família e vislumbrar a sua reprodução.

\section{Importância socioeconômica e os alimentos autoconsumidos: a produção para o autoconsumo nos municípios-caso.}

Os dados indicam que a produção para o autoconsumo foi uma estratégia recorrida por todos os estabelecimentos pesquisados (238), 
confirmando que esta prática faz parte do modo de vida das famílias rurais contemporâneas. Esta produção se faz presente principalmente por proporcionar uma alimentação "mais natural, sem veneno" e também "porque senão a gente tem que comprar". Há a percepção de que produzir para o consumo familiar é uma forma de economizar recursos financeiros e uma importante fonte de segurança alimentar, sobretudo pelo acesso e qualidade dos alimentos. Além disso, as unidades familiares mantêm o autoconsumo como uma atividade que dá prazer, "eu planto porque eu gosto também” (I 36, MR), e porque "a gente está na colônia, tem que criar estas coisas" (I 20, TP), ou seja, isto faz parte da identidade das unidades familiares, do "ethos de colono”, como referiram Tedesco (1999) e Seyferth (1974).

No depoimento abaixo é possível observar novamente algumas das justificativas expostas, mormente no que concerne ao fato de não precisar comprar a alimentação e pela qualidade sanitária desta, e também um pouco da diversidade que compõem esta produção. É possível evidenciar em poucas linhas que se trata de uma gama diversa de alimentos provenientes da criação animal, da horta, do pomar, da lavoura e da transformação caseira. Galinhas, porcos, bezerros, ovos, leite, mandioca, batata-doce, batata inglesa, frutas e hortaliças, são alguns exemplos. Enfim, "se planta de tudo um pouco".

Leite, ovos, carne, batatinha, batata-doce, mandioca, amendoim. Até amendoim eu to vendendo o que sobra. Tudo que hortaliças, frutas. Planto pra não precisar compra. Cebola também. O que a gente pode produzir. E tem a vantagem que não têm agrotóxicos (I 10, SM).

A presença generalizada da produção para o autoconsumo entre os agricultores familiares também é confirmada pelas informações da Tabela 02, que apresenta a importância da horta e do pomar nos estabelecimentos pesquisados. Evidencia-se que a maioria dos estabelecimentos familiares preza por possuir horta $(92,1 \%)$ e pomar $(89,9 \%)$, e não há discrepâncias entre os universos pesquisados. A diferença mais expressiva refere-se à presença de horta: enquanto em Veranópolis 98,3\% dos estabelecimentos a possuem, em Morro Redondo este percentual se reduz para $87,1 \%$. 
Tabela 02 - Presença de horta e pomar, e a suficiência destes em porcentagem (\%) para o consumo familiar nos estabelecimentos pesquisados.

\begin{tabular}{l|c|c|c|c}
\hline \multicolumn{3}{|c}{ HORTA } & \multicolumn{2}{c}{ POMAR } \\
Município & $\begin{array}{c}\text { Presença nos } \\
\text { Estabelecimen- } \\
\text { tos (\%) }\end{array}$ & $\begin{array}{c}\text { Suficiência para } \\
\text { consumo fami- } \\
\text { liar (\%) }\end{array}$ & $\begin{array}{c}\text { Presença nos } \\
\text { Estabelecimen- } \\
\text { tos (\%) }\end{array}$ & $\begin{array}{c}\text { Suficiência para } \\
\text { consumo fami- } \\
\text { liar (\%) }\end{array}$ \\
\hline $\begin{array}{l}\text { Veranópolis } \\
\begin{array}{l}\text { Morro } \\
\text { Redondo }\end{array}\end{array}$ & 98,3 & 93,1 & 86,4 & 86,3 \\
$\begin{array}{l}\text { Salvador } \\
\text { das Missões }\end{array}$ & 93,1 & 68,5 & 87,1 & 52,5 \\
$\begin{array}{l}\text { Três } \\
\text { Palmeiras }\end{array}$ & 89,8 & 75,9 & 91,4 & 69,8 \\
\hline Total & 92,1 & 93,1 & 94,9 & 87,5 \\
\hline
\end{tabular}

Fonte: Pesquisa AFDLP - UFRGS/UFPel/CNPq (2003).

A produção da horta é exaltada como uma produção isenta de agrotóxicos, ecológica e saudável, e por isto justifica-se sua existência. "A horta a gente já tem mais por causa dos agrotóxicos. A gente planta estas coisas assim, a gente colhe e sabe o que come. É mais limpo, bem mais saudável” (I 05, SM). A mesma fundamentação é dirigida ao pomar, com a ressalva de que "o gosto é bem melhor quando tu pode ir no pé [da fruteira] arrancar” (I 07, SM).

Argüidos sobre a suficiência da horta e do pomar para atender as necessidades alimentares (ainda Tabela 02), os entrevistados responderam de forma diferenciada, sendo que a horta atende de modo superior a este quesito, $82,6 \%$, se comparado com o pomar, $74 \%$. Entre os municípios pesquisados, as diferenças se aceraram. Ao passo que em Três Palmeiras, a horta e o pomar atendem de modo suficiente o consumo da família em $93,1 \%$ e $87,5 \%$ dos estabelecimentos respectivamente, em Morro Redondo esta mesma condição é alcançada por apenas $68,5 \%$ e $52,5 \%$ dos estabelecimentos, respectivamente. A insuficiência pode ser atribuída às dificuldades de produzir determinados cultivos em virtude de condições climáticas, pouca diversificação, preferência por produtos forâneos, limitação de área, opção da família por não produzir etc.

A Tabela 03 revela os valores anuais estimados pelos entrevistados aos produtos da horta e do pomar. Vale ressaltar que esta é uma pergunta 
que oferece elevado grau de dificuldade para obter uma resposta precisa, dado que raramente os agricultores contabilizam seus gastos, principalmente quando se trata da produção para o consumo da própria família. Mesmo assim, segundo Carneiro et al. (2003), os próprios agricultores se surpreendem de fronte aos valores estimados, reconhecendo a importância desta produção. Os números indicam uma ordem decrescente entre os universos pesquisados quanto aos valores médios do autoconsumo (horta e pomar somados): Veranópolis (R\$754,15), Salvador das Missões (R \$ 686,51), Três Palmeiras (R \$ 406,91) e Morro Redondo $(394,03)$. Levanta-se a hipótese de que em Veranópolis e Salvador das Missões a produção para o consumo familiar é mais valorizada pelas unidades familiares e que esta produção se diferencia segundo dinâmicas distintas da agricultura familiar.

Tabela 03 - Valor em reais ( $\mathrm{R} \$$ ) atribuído pelos entrevistados aos produtos da horta e do pomar.

\begin{tabular}{l|c|c|c}
\hline \multirow{2}{*}{ Município } & \multicolumn{3}{|c}{ Valor anual médio (R\$) } \\
& Horta & Pomar & Total (médio) \\
\hline Veranópolis & 830,65 & 677,65 & 754,15 \\
Morro Redondo & 475,06 & 313,00 & 394,03 \\
Salvador das Missões & 689,22 & 683,81 & 686,51 \\
Três Palmeiras & 397,42 & 416,41 & 406,91 \\
\hline Total & 598,09 & 522,72 & 560,40 \\
\hline
\end{tabular}

Fonte: Pesquisa AFDLP - UFRGS/UFPel/CNPq (2003)

Nos municípios estudados, os principais produtos cultivados na horta foram: alface, beterraba, cebola, cenoura, couve, salsa, repolho, tomate, alho, radite, rúcula, couve-flor, pimentão, moranga, brócolis, pepino, vagem, chuchu, ervilha, rabanete e espinafre. Outros também foram citados (alcachofra, fava, espinafre, chicória etc.), mas com freqüência pouco significativa, em apenas um município. A Tabela 04 apresenta as cinco olerícolas mais freqüentes em termos de números de estabelecimentos que produziram para o autoconsumo nos universos pesquisados. É interessante observar que entre estas cinco, freqüentemente está presente alface, repolho, beterraba e cenoura, indicando 
uma possível homogeneização nos hábitos alimentares.

Hábitos alimentares são definidos por Bleil (1998), citando Mead e Guthe (1945), como porções do conjunto de alimentos disponíveis a indivíduos ou grupos de indivíduos, que são selecionadas, utilizadas e consumidas em resposta a pressões sociais e culturais. Igualmente Woortmann (1978) afirma que os hábitos alimentares dependem, por um lado, das condições de acesso aos alimentos em função da posição dos indivíduos e grupos no processo produtivo, e, por outro, da seletividade advinda do processo cultural, justamente por ser a alimentação um fenômeno cultural.

Tabela 04 - As cinco olerícolas mais freqüentes em termos de números de estabelecimentos (n) que produziram para o autoconsumo nos universos pesquisados.

\begin{tabular}{l|c|l|c|l|c|l|c}
\hline \multicolumn{2}{c|}{ Veranópolis } & \multicolumn{2}{c}{ Morro Redondo } & \multicolumn{2}{c}{ Salvador das Missões } & \multicolumn{2}{c}{ Três Palmeiras } \\
\multicolumn{1}{c|}{ olerícolas } & $\mathrm{n}$ & olerícolas & $\mathrm{n}$ & Olerícolas & $\mathrm{n}$ & olerícolas & $\mathrm{n}$ \\
\hline Radite & 57 & Alface & 53 & Repolho & 52 & Alface & 52 \\
Alface & 57 & Couve & 51 & Cebola & 51 & Salsa & 48 \\
Cenoura & 51 & Beterraba & 47 & Alface & 49 & Repolho & 46 \\
Repolho & 50 & Salsa & 47 & Beterraba & 48 & Beterraba & 46 \\
Cebola & 46 & Repolho & 44 & Cenoura & 48 & Cenoura & 46 \\
\hline
\end{tabular}

Fonte: Pesquisa AFDLP - UFRGS/UFPel/CNPq (2003).

Quanto ao pomar, em todos os municípios, foram encontradas as seguintes frutíferas: videira, pessegueiro, macieira, laranjeira, bergamoteira, abacateiro, pereira, goiabeira, caquizeiro, figueira e limoeiro. Além destas, em Veranópolis e Três Palmeiras foram citadas: ameixeira, mamoeiro, pitangueira, nogueira, bananeira, romãzeira, jabuticabeira e kiwi. A Tabela 05 apresenta as cinco frutíferas mais assíduas em termos de número de estabelecimentos que produziram para autoconsumo. Embora o pomar não sinalize tanto quanto a horta para a homogeneização dos hábitos alimentares, é interessante ressaltar a predominância dos citros sobre as demais frutíferas em todos os municípios estudados, igualmente observado por Wagner, Marques e Menasche (2007) na região do Vale do Taquari (RS). 
Tabela 05 - As cinco frutíferas mais freqüentes em termos de números de estabelecimentos (n) que produziram para o autoconsumo nos universos pesquisados.

\begin{tabular}{l|c|l|c|l|c|l|c}
\hline \multicolumn{2}{c|}{ Veranópolis } & \multicolumn{2}{c}{ Morro Redondo } & \multicolumn{2}{c}{ Salvador das Missões } & \multicolumn{2}{c}{ Três Palmeiras } \\
\multicolumn{1}{c|}{ frutíferas } & $\mathrm{n}$ & frutíferas & $\mathrm{n}$ & frutíferas & $\mathrm{n}$ & frutíferas & $\mathrm{n}$ \\
\hline Laranjeira & 50 & Laranjeira & 53 & Laranjeira & 53 & Laranjeira & 57 \\
Bergamoteira & 50 & Bergamoteira & 53 & Bergamoteira & 52 & Bergamoteira & 55 \\
Limoeiro & 43 & Limoeiro & 47 & Pessegueiro & 48 & Pessegueiro & 49 \\
Videira & 41 & Goiabeira & 45 & Videira & 37 & Caquizeiro & 39 \\
Figueira & 39 & Figueira & 39 & Limoeiro & 36 & Pereira & 38 \\
\hline
\end{tabular}

Fonte: Pesquisa AFDLP - UFRGS/UFPel/CNPq (2003)

Tabela 06 - Presença de transformação caseira para o consumo familiar nos estabelecimentos pesquisados.

\begin{tabular}{l|c|c}
\hline \multirow{2}{*}{ Município } & \multicolumn{2}{|c}{ Transformação caseira } \\
& Sim (\%) & Não (\%) \\
\hline Veranópolis & 96,6 & 03,4 \\
Morro Redondo & 87,1 & 12,9 \\
Salvador das Missões & 93,1 & 06,9 \\
Três Palmeiras & 96,6 & 03,4 \\
\hline Total & 93,3 & 06,7 \\
\hline
\end{tabular}

Fonte: Pesquisa AFDLP - UFRGS/UFPel/CNPq (2003).

Outra dimensão da produção para o autoconsumo analisada diz respeito à transformação caseira. Segundo a Tabela 06, a proporção de famílias que possuem alguma forma de transformação caseira para o consumo familiar é elevada em todos os municípios, alcançando 96,6 \% dos estabelecimentos em Veranópolis e Três Palmeiras. O valor mais baixo (mas nem por isso pouco significante) é encontrado em Morro Redondo (87,1\%), resultado que acompanha a Tabela 03.

Muitos alimentos são provenientes da transformação caseira e fazem parte da dieta alimentar diária das famílias, como: queijo, salame, vinho, banha, schmier/doces, conservas (pepino, pêssego, etc.), açúcar mascavo, massa de tomate, cachaça, rapadura, melado e massa caseira (pão, cuca etc.). A Tabela 07 apresenta os cinco produtos da 
transformação caseira mais freqüentes em termos de número de estabelecimentos que produziram para o autoconsumo. Embora a assiduidade seja diferente entre os municípios, é importante mencionar que dentre os cinco, quatro são comuns a todos (schmier, banha, queijo e salame). É nestes produtos que fica mais evidente a influência da cultura nos hábitos alimentares, a exemplo do predomínio de queijo, salame e vinho em Veranópolis, produtos tipicamente italianos, e a dominância de schmier/doce e salame (ou lingüiça, como denominam os alemães) em Salvador das Missões, influência da cultura alemã.

Tabela 07 - Os cinco produtos da transformação caseira mais freqüentes em termos de número de estabelecimentos (n) que produziram para o autoconsumo nos municípios pesquisados.

\begin{tabular}{l|c|l|c|l|l|l|l}
\hline \multicolumn{2}{c|}{ Veranópolis } & \multicolumn{2}{c}{ Morro Redondo } & \multicolumn{2}{c}{ Salvador das Missões } & \multicolumn{2}{c}{ Três Palmeiras } \\
\multicolumn{1}{c|}{ Alimentos } & $\mathrm{N}$ & Alimentos & $\mathrm{N}$ & Alimentos & $\mathrm{N}$ & Alimentos & $\mathrm{N}$ \\
\hline Queijo & 47 & schmier & 43 & schmier & 49 & banha & 53 \\
Salame & 46 & banha & 32 & banha & 41 & salame & 39 \\
Banha & 45 & conservas & 19 & salame & 40 & queijo & 30 \\
Schmier & 39 & salame & 16 & conservas & 38 & schmier & 27 \\
Vinho & 33 & queijo & 07 & queijo & 26 & melado & 20 \\
\hline
\end{tabular}

Fonte: Pesquisa AFDLP - UFRGS/UFPel/CNPq (2003)

O autoconsumo de alimentos provenientes da lavoura também foi considerado. Para Herédia (1979), seriam estes os responsáveis pela "comida" da unidade familiar. O termo "comida", aqui, significa a base da dieta alimentar. Não dispor destes, mesmo que havendo produtos da horta, pomar, transformação caseira e criação animal, a família "passaria fome” (HERÉDIA, 1979). Conquanto estes alimentos continuem sendo a base do prato diário, como o feijão, mandioca e batatas, considera-se não que estes perderam importância, mas que outros também ganharam maior notoriedade, como as frutas e verduras, sobretudo por garantirem uma alimentação saudável. Outrossim, a criação animal passa a ter maior importância. No estudo realizado por Cândido (2001), a presença da carne era esporádica, presente em refeições e dias especiais (como os domingos), contudo nos dias de hoje é corriqueira, compondo a mesa 
cotidianamente: “[...] a gente se acostumou de ter todos os dias um pedacinho de carne, mesmo que seja pequeno" (I 43, MR).

A comparação demonstra que o grupo de alimentos provenientes da lavoura foi praticamente o mesmo nos quatro municípios, sendo eles: feijão, batata-doce, batata inglesa, mandioca, cana-de-açúcar e amendoim. A Tabela 08 apresenta os cinco produtos mais assíduos em termos de número de estabelecimentos que os produziram para o consumo familiar. Três destes (feijão, batata-doce e mandioca) são comuns entre os universos pesquisados, demonstrando mais uma vez homogeneidade nos hábitos alimentares.

Tabela 08 - Os cinco alimentos provenientes da lavoura mais freqüentes em termos de números de estabelecimentos (n) que produziram para o autoconsumo nos municípios pesquisados.

\begin{tabular}{l|c|c|c|l|l|l|l}
\hline \multicolumn{2}{c|}{ Veranópolis } & \multicolumn{2}{c}{ Morro Redondo } \\
\multicolumn{1}{c|}{ alimentos } & $\mathrm{N}$ & alimentos & $\mathrm{n}$ & alimentos & $\mathrm{n}$ & \multicolumn{1}{c}{ alimentos } & $\mathrm{n}$ \\
\hline feijão & 40 & feijão & 41 & mandioca & 44 & mandioca & 53 \\
batata-doce & 39 & batata inglesa & 30 & cana-de-açúcar & 40 & batata-doce & 44 \\
mandioca & 38 & batata-doce & 18 & batata-doce & 23 & feijão & 42 \\
batata inglesa & 15 & mandioca & 02 & feijão & 17 & cana-de-açúcar & 30 \\
cana-de-açúcar & 09 & milho & 01 & batata inglesa & 12 & arroz & 12 \\
\hline
\end{tabular}

Fonte: Pesquisa AFDLP - UFRGS/UFPel/CNPq (2003).

Arroz e trigo, dois cereais importantes na alimentação, somente foram encontrados em dois municípios e em poucos estabelecimentos. As dificuldades de beneficiamento relativas à localização das beneficiadoras e custos para pequenas quantidades podem ser fatores que contribuem para esta condição. Também pode ser justificado, no caso do arroz, o fato de que "O pessoal perdeu o hábito e os banhados que tinham foram drenados pra plantá soja e milho. Então arroz tem uns dois, três, quatro no máximo que ainda produzem pro consumo deles e o resto do pessoal compra” (I 16, SM). Quanto ao trigo, naquelas poucas unidades familiares que ainda o produzem, a maioria entrega o produto bruto para uma cooperativa, sendo parte do valor pago em farinha, retirada aos poucos, conforme a necessidade da família. 
“Farinha de trigo, até agora nós não compremos. Agora faz dois anos que não plantemos trigo, mas temos farinha lá [cooperativa] pra mais um ano quase” (I 25, TP).

A criação de animais domésticos também é uma fonte importante de alimentação para família. Segundo Garcia Jr. (1983), a criação é uma atividade que se presta à reserva e acumulação. Reserva porque faz face ao consumo alimentar da família, tanto de forma direta (consumo de carne) como de forma indireta (produção de leite, ovos etc.). Acumulação porque não havendo necessidade de consumo, basta garantir a alimentação dos animais para que eles se reproduzam. Ademais, não existindo mais esta possibilidade e sem demanda de consumo da família, pode-se recorrer à venda, ampliando os recursos monetários desta.

Nas unidades familiares investigadas, o principal motivo para a manutenção desta produção está vinculado à insegurança oriunda do desconhecimento da sanidade e do manejo da carne comercializada nos mercados. Há a compreensão de que produzindo os próprios animais para o consumo familiar assegura-se a qualidade, derivada do conhecimento de como criá-los e do manejo mais natural a que são submetidos estes animais vis-à-vis àqueles comprados. “(...) não adianta tu compra as coisas, tu não sabe o que tu come. Criação doente, daí morrem, daí vendem no mercado e o pessoal come e nem sabe o que estão comendo. Eu não sou assim, eu engordo uns bichinhos ali. Um gado sempre tenho, estou com o freezer cheio" (I 24, TP).

Foram encontrados os seguintes animais destinados ao consumo familiar nos universos pesquisados: galinha caipira, suíno, novilho, vaca, frango de corte, touro e terneiro. Além destes, em Morro Redondo e Três Palmeiras foram citados: pato, boi e ovino. Os cinco mais freqüentes em termos de número de estabelecimentos que os produziram para o consumo são encontrados na Tabela 09. Em todos os municípios há predominância do consumo de galinha caipira e suínos, o que pode ser justificado pelo fato destes animais geralmente serem alimentados com produtos do próprio estabelecimento, até mesmo com os resíduos de alimentos da família.

Durante o trabalho de campo em Morro Redondo, vários entrevistados citaram a diminuição do autoconsumo de carne suína em virtude de que “(...) dizem que faz mal a carne de porco, a gordura. Quando 
nós era pequeno sempre criava, agora não, tem algum que cria aqueles porcão grande, branco, mas antigamente era aquele de banha, eu criava muito" (I 39, MR). Várias famílias possuem a compreensão que a "carne de porco" compromete a saúde e, por isso, diminuíram ou abandonaram a produção de suínos. Ainda em relação a este município e ao consumo de criação animal, é mister mencionar que o açougue sempre esteve muito presente na vida das famílias rurais, “(...) não é que nem no norte do estado. Carne de rês, o pessoal, aqui, nunca criou pra consumo próprio. Claro, tem quem crie, mas a maioria... Hoje praticamente ninguém mais cria porco, até nos açougue vendem carne de porco" (I 41, MR). A freqüência de estabelecimentos que produzem algum tipo de bovino (novilha, vaca, terneiros) e suínos para o consumo familiar neste município é a menor comparativamente os demais (Tabela 09).

Tabela 09 - As cinco criações animais mais freqüentes em termos de números de estabelecimentos (n) que produziram para o autoconsumo nos municípios pesquisados.

\begin{tabular}{|l|c|l|c|c|c|c|c|}
\hline \multicolumn{2}{|c|}{ Veranópolis } & \multicolumn{2}{c|}{ Morro Redondo } & \multicolumn{2}{c|}{$\begin{array}{c}\text { Salvador das } \\
\text { Missões }\end{array}$} & \multicolumn{2}{c|}{ Três Palmeiras } \\
\hline \multicolumn{1}{|c|}{ alimentos } & $\mathrm{n}$ & alimentos & $\mathrm{n}$ & alimentos & $\mathrm{n}$ & alimentos & $\mathrm{n}$ \\
\hline suíno & 49 & galinha caipira & 48 & galinha caipira & 41 & Suíno & 55 \\
\hline galinha caipira & 45 & suíno & 37 & suíno & 41 & galinha caipira & 28 \\
\hline vaca & 28 & novilha & 05 & terneiro & 30 & frango de corte & 26 \\
\hline frango de corte & 09 & vaca & 05 & frango de corte & 25 & terneiro & 22 \\
\hline terneiro & 06 & frango de corte & 03 & vaca & 23 & Vaca & 15 \\
\hline
\end{tabular}

Fonte: Pesquisa AFDLP - UFRGS/UFPel/CNPq (2003).

A Tabela 10 apresenta o autoconsumo de leite, ovos, peixe e mel para os universos estudados. Os dados não apresentam discrepâncias em torno do número de estabelecimentos que produzem cada alimento, embora se consiga visualizar diferenças em Morro Redondo. Neste município, exceto no caso do leite, o número de estabelecimentos que mantêm ovos, peixe e mel para o autoabastecimento é sempre menor que nos demais municípios. 
Tabela 10 - Autoconsumo de leite, ovos, peixes e mel, segundo a freqüência de estabelecimentos (n) que produziram para o autoconsumo nos municípios pesquisados.

\begin{tabular}{l|c|c|c|c}
\hline \multicolumn{1}{c|}{ Alimento } & Veranópolis & Morro Redondo & Salvador das Missões & \multicolumn{1}{c}{ Três Palmeiras } \\
\hline leite & 48 & 55 & 51 & 55 \\
ovos & 21 & 14 & 20 & 17 \\
peixe & 51 & 47 & 54 & 52 \\
mel & 21 & 09 & 30 & 20 \\
\hline
\end{tabular}

Fonte: Pesquisa AFDLP - UFRGS/UFPel/CNPq (2003).

Parte destes produtos, e dos demais citados, também são destinados à comercialização, como é o caso dos ovos, leite, uva, citros, pêssego, feijão, milho etc. Alguns de modo mais esporádico, como vacas, suínos, peixes etc. Esta dupla face (consumo e venda) se deve a marca da alternatividade presente nestes produtos, conferindo além de ingresso monetário, maior autonomia às unidades familiares.

Quanto a esta interface entre produtos destinados ao autoconsumo e à comercialização, é importante destacar que no caso de Veranópolis, os mesmos coincidem. Segundo dados da pesquisa AFDLP (2003), os produtos vendidos com maior freqüência em termos de número de estabelecimentos no ano agrícola da pesquisa foram: uva (30 estabelecimentos), laranja (21), bergamota (20) e milho (13) - que possibilitam ao mesmo tempo o consumo pelas famílias. Similarmente ocorre em Morro Redondo, onde os quatros produtos vendidos mais citados foram: pêssego (21 estabelecimentos), feijão (20), milho (12) e batatinha (10). Estes dados comprovam a marca da alternatividade discutida por Herédia (1979) e Garcia Jr. (1983). Todavia, em Salvador das Missões e Três Palmeiras há o predomínio das commodities sobre os produtos com esta característica, sendo as principais, soja (vendido por 50 estabelecimentos ), milho (19), trigo (12) e tungue (2) no primeiro, e soja (45), milho (23), feijão (21) e trigo (8) no segundo. Essa diferença justifica-se pelo fato de que nos dois últimos municípios a modernização da agricultura atuou de forma intensiva e consolidou o binômio soja-trigo, alterando as estratégias de reprodução das unidades familiares. 
O exposto acima levanta dúvidas em relação à afirmação de Garcia Jr. (1989, p.127, grifos no original) de que “(...) quanto maior a ameaça ao consumo doméstico e à reprodução social camponesa, maior será a tendência ao princípio da alternatividade operar. E ao inverso, quanto maior a estabilidade das condições sociais de produção e consumo e da reprodução destas condições, maior será a tendência à especialização em lavouras comerciais, a se transformar num farmer”. Segundo os dados apresentados, em Veranópolis, onde as condições de produção e reprodução são comparativamente mais estáveis, o princípio da alternatividade é mais vigente que em Três Palmeiras, onde as condições de (re)produção são mais instáveis. Isto remete à existência de outros fatores que interferem no cultivo de produtos com a marca da alternatividade, como por exemplo, o processo de modernização da agricultura, o ciclo demográfico e os mercados locais.

A Tabela 11 apresenta os valores monetários anuais do conjunto de alimentos destinados ao autoconsumo investigados pela pesquisa, diferenciados quanto à origem (animal e vegetal) e o total. Verifica-se que se trata de valores expressivos, alcançando o valor total anual médio de $\mathrm{R}$ \$ 4.308,08 em Veranópolis, R \$ 2.161,05 em Morro Redondo, R\$ 4.223,88 em Salvador das Missões e em Três Palmeiras, R\$3.026,02.

Quanto às diferenças entre os universos sociais pesquisados, os resultados desta Tabela são semelhantes à Tabela 3. Os valores são mais expressivos em Veranópolis, seguido por Salvador das Missões, Três Palmeiras e Morro Redondo. Chama atenção o fato de Morro Redondo apresentar um produto bruto de autoconsumo total ${ }^{8}$ médio correspondente a 50,16\% de Veranópolis. Comparativamente aos demais, naquele município é mais notável a diminuição do autoconsumo e a mercantilização da produção de alimentos. O caso mais emblemático, onde a família somente produz para o consumo o leite, é explicitado abaixo quando argüido se produzia "pro gasto". Os custos de produção, a sazonalidade desta, o trabalho envolvido e o preço dos

${ }^{8}$ Lembrando que se denomina produto bruto de autoconsumo total, o valor referente ao somatório: quantidade de produtos vegetais autoconsumidos multiplicado pelo valor de venda destes alimentos, mais, quantidade de animais autoconsumidos multiplicado pelo valor de venda destes alimentos. Ressalta-se ainda que se trata de valores brutos, ou seja, não foram descontados os custos de produção e a depreciação. 
alimentos no mercado (tanto de venda como de compra) são argumentos lançados para justificar a compra de praticamente tudo que é consumido pelo casal. Embora não esteja presente no fragmento da entrevista, é mister ressaltar que se trata de um casal de aposentados, cuja idade se aproxima aos 70 anos, corroborando com a decisão de parar de produzir para o autoabastecimento alimentar.

Nada, batata eu compro, feijão eu compro, milho eu compro, o porco eu compro, verdura, tudo se compra [...]. Mas sai mais barato. Dois anos atrás eu plantei milho, o saco de milho que eu colhi saiu $\mathrm{R} \$ 33,00$, e no mercado estava R\$20,00. Eu vou plantar ainda? Tira do meu salário pra botar na terra? Pra eu e ela [esposa] me judiar? Não. É mais vantagem comprar. Porque se ela vai na horta plantar 20 pés de repolho, 20 pés de alface, 20 de beterraba, enfim, fica pronta e eu tenho que consumir ela, aí outro mês eu não tenho porque ela terminou e, assim, eu compro. Eu gasto menos do que se eu fosse plantar. Um repolho assim tu compra é um real e pra nós dá um mês, a gente não faz todos os dias mesmo. Tu quer ver a minha horta vai lá na geladeira. Lá na geladeira tem cada beterraba e alface assim. A gente compra, guarda, tem, não se incomoda (I $37, \mathrm{MR})$.

A Figura 02 apresenta o produto de autoconsumo total separado por estratos de valores e o número de estabelecimentos pertencentes a cada um deles, tornando mais nítidas as diferenças entre universos pesquisados e também dentro destes. Enquanto em Veranópolis apenas $1,69 \%$ dos estabelecimentos pesquisados apresentam produto bruto de autoconsumo total menor à R \$ 1.000,00, em Morro Redondo, 19,35\% dos estabelecimentos encontram-se neste estrato. Em Salvador das Missões e Três Palmeiras, as proporções são, respectivamente, 5,17\% e $6,78 \%$. Já a porcentagem de estabelecimentos no estrato do produto de autoconsumo total maior que R \$ 5.000,00 em Veranópolis é 32,21\% vis-à-vis 3,23\% em Morro Redondo, 25,87\% em Salvador das Missões e 10,17\% em Três Palmeiras. Esta heterogeneidade permite afirmar que a produção para o consumo familiar, em termos de importância econômica, é uma estratégia com acentuada diversidade. 
Tabela 11 - Produto Bruto de autoconsumo animal, vegetal e total (valor médio anual em $\mathrm{R} \$$ ) nos estabelecimentos pesquisados.

\begin{tabular}{l|c|c|c|c|c}
\hline \multirow{2}{*}{ Município } & \multicolumn{3}{|c}{ Produto Bruto do Autoconsumo médio anual em Reais (R\$) e } \\
& \multicolumn{2}{|c|}{ Vegetal } & A & Animal & Total \\
& $\mathrm{R} \$$ & $\%$ & $\mathrm{R} \$$ & $\%$ & \\
\hline Veranópolis & $2.414,17$ & 56,04 & $1.894,31$ & 43,96 & $4.308,08$ \\
Morro Redondo & $1.081,39$ & 50,04 & $1.079,66$ & 49,96 & $2.161,05$ \\
Salvador das Missões & $2.026,01$ & 47,97 & $2.197,87$ & 52,03 & $4.223,88$ \\
Três Palmeiras & $1.425,48$ & 47,11 & $1.600,00$ & 52,89 & $3.026,02$ \\
\hline Total & $1.736,76$ & 50,63 & $1.692,96$ & 49,37 & $3.430,02$ \\
\hline
\end{tabular}

Fonte: Pesquisa AFDLP - UFRGS/UFPel/CNPq (2003).

Figura 02: Estratos do Produto Bruto de Autoconsumo Total em reais e o número de estabelecimentos presentes em cada um deles nos universos pesquisados.

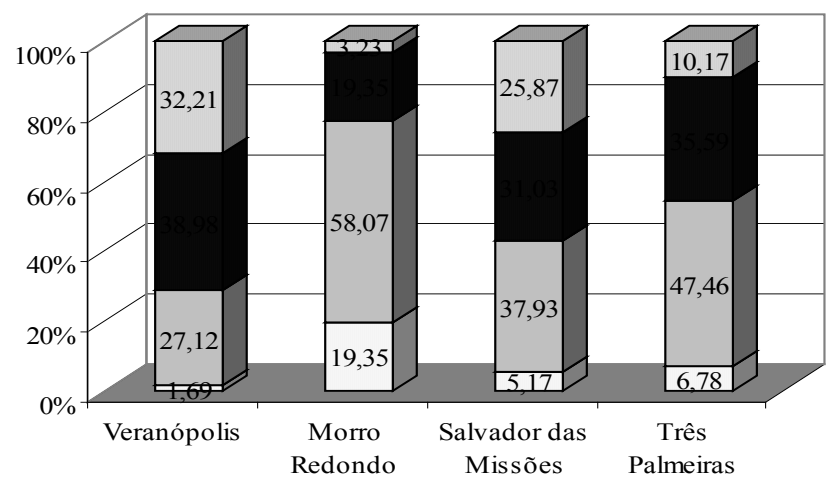

$\square$ maior à $5.000,00$

- $3.000,01-5.000,00$

$\square 1.000,01-3.000,00$

$\square$ menor à $1.000,00$

Fonte: Pesquisa AFDLP - UFRGS/UFPel/CNPq (2003).

Vários fatores contribuem para esta diversidade, dentre estes citam-se: as características das famílias em cada região (número de membros, consumidores, UTH's); as condições técnicas de produção (área total, acesso a assistência técnica e crédito, capital disponível em máquinas); os tipos de cultivos e produção agropecuária praticados; as diferentes fontes de renda (renda agrícola, não-agrícola, previdência social); o repertório cultural das famílias e municípios e; o contexto 
local. Estes são alguns dos fatores (sempre expressando-se de forma diferenciada segundo cada dinâmica da agricultura familiar), que isolados ou em conjunto, uns de forma mais expressiva que outros, determinam a intensidade da produção para o autoconsumo. ${ }^{9}$

Em que pese esta diversidade, em todos os casos estudados esta produção permanece muito relevante para a reprodução social das unidades familiares, como é demonstrado nas Tabelas que seguem. Através da Tabela 12, é possível evidenciar que em média $28,88 \%$ do produto bruto total e $27,24 \%$ da renda total é fruto da produção para o autoconsumo, contribuindo significativamente para a condição econômica das famílias. Em outras palavras, em Três Palmeiras e Morro Redondo, casos mais expressivos, as unidades familiares deixam de gastar, respectivamente, $38,34 \%$ e $32,01 \%$ da renda total anual com a aquisição de alimentos nos mercados, confirmando que se trata de uma forma de "economização", como cunhou Lovisolo (1989). Cabe considerar ainda para estes casos a extrema relevância do autoconsumo, dado que a proporção desta produção no produto bruto total $(31,80 \%$ e $25,50 \%$, respectivamente) é inferior quando na renda total $(38,34 \%$ e $32,01 \%$, sucessivamente). Isto significa que, descontado os custos de produção e somando as outras possíveis rendas, a importância do autoconsumo é acentuada. Em Salvador das Missões e Veranópolis, as porcentagens em relação à renda total anual são menores, resultado desta ser mais elevada comparativamente aos demais municípios (Ver Tabela 01), fato que dilui a importância relativa do autoconsumo.

A Tabela 13, complementando a anterior, compara o valor monetário do produto bruto de autoconsumo total por consumidor ${ }^{10} \mathrm{com}$ o custo médio da cesta básica (R\$ 132,21 reais) ${ }^{11}$. Este procedimento

\footnotetext{
${ }^{9}$ A influência de cada um destes fatores na produção para o autoconsumo encontra-se discutida no Capítulo 04 da dissertação da qual este artigo é oriundo - Grisa (2007). Por conta dos objetivos delimitados para este trabalho não é retomado este debate aqui.

${ }^{10}$ Segundo Tavares dos Santos (1984), considera-se uma unidade de consumidor um indivíduo com idade superior a nove anos, enquanto as crianças até nove anos correspondem à meia unidade consumidor.

${ }^{11}$ Tomou-se como referência o custo médio da cesta básica na capital do Rio Grande do Sul no ano agrícola da pesquisa (set./2001 - ago./2002), segundo valores divulgados pelo DIEESE. Deve-se considerar que o custo da cesta básica em Porto Alegre é um dos mais elevados do país, podendo subestimar o valor o autoconsumo. Outro fator que contribui para a subestimação é o fato do autoconsumo estar sendo mensurado pelo preço de venda dos alimentos, enquanto a cesta básica considera os preços de compra.
} 
permite comparar a produção "pro gasto” com o valor monetário necessário para alimentar um indivíduo em idade adulta, embora desconsiderando o balanço nutricional.

Tabela 12 - Proporção do produto bruto autoconsumo total sobre o produto bruto total e a renda total anual nos municípios pesquisados.

\begin{tabular}{l|c|c}
\hline & \multicolumn{2}{c}{ Proporção do produto bruto do autoconsumo (\%) sobre } \\
& o produto bruto total anual & a renda total anual \\
\hline Veranópolis & 29,39 & 21,87 \\
Morro Redondo & 25,50 & 32,01 \\
Salvador das Missões & 28,82 & 16,73 \\
Três Palmeiras & 31,80 & 38,34 \\
\hline Total & 28,88 & 27,24 \\
\hline
\end{tabular}

Fonte: Pesquisa AFDLP (2003)

Tabela 13 - Proporção do valor do produto bruto autoconsumo total por consumidor sobre o custo da cesta básica (POA, 2001/2002).

\begin{tabular}{l|c}
\hline \multicolumn{1}{c}{ Município } & Proporção no custo da cesta básica (\%) \\
\hline Veranópolis & 68,31 \\
Morro Redondo & 42,67 \\
Salvador das Missões & 69,09 \\
Três Palmeiras & 54,22 \\
\hline Total & 58,33 \\
\hline
\end{tabular}

Fonte: Pesquisa AFDLP (2003) e DIEESE

Em Veranópolis e Salvador das Missões, onde o autoconsumo é uma estratégia mais valorizada pelas unidades familiares, o autoabastecimento responde, aproximadamente, a $70 \%$ do custo da cesta básica (Tabela 13). Nestes, as unidades familiares deixam de gastar em torno de $\mathrm{R} \$ 90,00$ por mês com alimentação. Morro Redondo e Três Palmeiras apresentam valores inferiores, $42,67 \%$ e $54,22 \%$ respectivamente, mas nem por isso desprezíveis. Não obstante as diferenças, percebe-se mais uma vez, nos quatro municípios investigados, o potencial do autocosumo para a segurança alimentar e também como uma importante forma de economizar. 


\section{Considerações finais}

Como observado ao longo do trabalho, a produção para o autoconsumo está presente em $100 \%$ dos estabelecimentos pesquisados e configura-se como uma estratégia relevante para reprodução das unidades familiares. O trabalho procurou demonstrar que se trata de uma importante forma de economização e fonte de segurança alimentar para os agricultores, chegando a representar 38,34\% da renda total e 69,09\% dos custos de uma cesta básica.

No entanto, esta estratégia não apresenta a mesma intensidade em todos os estabelecimentos e nem é semelhante entre os municípios, do mesmo modo que a própria agricultura familiar é diversa entre estes. Localizados respectivamente na região nordeste e sul do estado, Veranópolis e Morro Redondo compõem as extremidades desta diferença. Enquanto o primeiro apresenta os valores mais elevados, o segundo depara-se com os inferiores. Salvador das Missões e Três Palmeiras apresentam valores intermediários, mas também discrepantes entre si. Além das diferenças entre municípios, o autoconsumo também se diferencia dentro destes, como demonstrado especialmente na Figura 02, onde se pode observar que em todos os municípios há estabelecimentos pertencentes aos quatro estratos de produto bruto de autoconsumo total estabelecidos. Estas diferenças são frutos das dinâmicas específicas de desenvolvimento da agricultura familiar desenvolvidas em cada região, que precisam ser melhores exploradas em trabalhos futuros.

Contudo, esta diversidade da produção para o autoconsumo não foi observada quando investigado os tipos de alimentos autoconsumidos. Embora as distâncias geográficas, os diferentes cultivos agrícolas, as distintas culturas e as dinâmicas de desenvolvimento da agricultura familiar em cada região, observou-se que há uma tendência à homogeneidade nos hábitos alimentares. Resultados semelhantes foram encontrados por Wagner, Marques e Menasche (2007) ao compararem três comunidades no Vale do Taquari (RS). Segundo as autoras, os produtos da lavoura ("roça") e pomar pouco se diferenciam entre as comunidades, sendo mais distinto os produtos da horta, fruto das diferenças étnicas e hábitos alimentares. Os dados deste trabalho, todavia, indicam homogeneidade também nos produtos da 
horta. Alface, beterraba, repolho, laranja, bergamota, queijo, salame, banha, schimier/doce, feijão, mandioca, batata-doce, batata inglesa, galinha caipira, suínos, leite e peixe foram alimentos presentes em quase todos os estabelecimentos pesquisados. A homogeneidade pode resultar de um conjunto de fatores, como perda de raízes culturais, aumento da disponibilidade de alimentos nos mercados e o acesso a estes pelas unidades familiares, influência dos meios de comunicação, entre outros.

De um modo geral, os dados apresentados questionam a premissa de que o autoconsumo é um tipo de produção arcaica e, como a enxada, seria substituído à medida que as unidades familiares mecanizam o processo produtivo e se inserem aos mercados. Também é refutada a marginalidade ou a insignificância que lhe é atribuída, pois trata-se de um tipo de produção recorrente para grande maioria dos agricultores e desempenha importantes funções.

Neste sentido, considera-se que este trabalho contribui para destacar a importância do tema e forneceu argumentos para que os organismos de planejamento e os formuladores de políticas passem a reconhecê-lo como mecanismo para a segurança alimentar e combate a pobreza rural. Acredita-se, por fim, que o fortalecimento da agricultura familiar e a promoção do desenvolvimento rural também passam por esta iniciativa.

\section{Referências}

ABRAMOVAY, R. Paradigmas do capitalismo agrário em questão. 2. ed. São Paulo: Hucitec, 1998. 275 p.

ANJOS, F.S et al. Abrindo a caixa-verde: estudo sobre a importância do autoconsumo na agricultura familiar gaúcha. In: XLII Congresso Brasileiro de Economia e Sociologia Rural. Cuiabá (MT): SOBER, Cd-Roan, 22 p., 2004.

BLEIL, S.I. O padrão alimentar ocidental: considerações sobre a mudança de hábitos no Brasil. Cadernos de Debate. São Paulo: NEPA/ UNICAMP, v. 6, 1998. p. 1-25. 
BRANDÃO, C.R. Plantar, colher, comer: um estudo sobre o campesinato goiano. Rio de Janeiro: Edições Graal, 1981. 181 p.

BRASIL. Instituto Brasileiro de Geografia e Estatística, IBGE, Censo Agropecuário 1995/1996. No 22, Rio Grande do Sul. Rio de Janeiro: Brasil, 1998

CÂNDIDO, A. Os parceiros do Rio Bonito: um estudo sobre o caipira paulista e a transformação dos seus meios de vida. 9. ed. São Paulo: Duas Cidades; Ed. 34, 2001. 376 p.

CARNEIRO, M.J. et al. Agricultura, preservação ambiental e turismo: desafios para uma agricultura multifuncional (Nova Friburgo, RJ). Rio de Janeiro, 2003. 47 p. Relatório de pesquisa.

CHAYANOV, A.V. Sobre a teoria dos sistemas econômicos não capitalistas. In: SILVA, J.G. da; STOLEKE, V. A questão agrária. São Paulo: Brasiliense, 1981. p. 133-63.

. La organización de la unidad económica campesina. Buenos Aires: Editora Nueva Vision, 1974. 342 p.

CONSELHO NACIONAL DE SEGURANÇA ALIMENTAR E NUTRICIONAL. Princípios e diretrizes de uma política de segurança alimentar e nutricional. Brasília (DF): 2004.

CONTERATO, M.A. A mercantilização da agricultura familiar no Alto Uruguai/RS: um estudo de caso no município de Três Palmeiras. Porto Alegre: Série PGDR/UFRGS (dissertação de mestrado), 2004. 209 f.

DEPARTAMENTO INTERSINDICAL DE ESTATÍSTICA E ESTUDOS SOCIOECONÔMICOS. Cesta básica nacional. 2002/2003. Disponível em: < http://www.dieese.org.br > . Acesso em: jun. 2006.

FEE - Fundação de Economia e Estatística Siegfried Emanuel Heuser / RS. FEE Dados. Disponível em: http://www.fee.rs.gov.br/ Acesso em jul./2006.

GARCIA FILHO, D.P. Guia metodológico: diagnóstico de sistemas agrários. Brasília: INCRA/FAO, 1999. 58 p.

GARCIA JR., A.R. Terra de trabalho: trabalho familiar de pequenos produtores. Rio de Janeiro: Paz e Terra, 1983. 236 p. 
. O sul: caminho do roçado: estratégias de reprodução camponesa e transformação social. São Paulo/Brasília: Marco Zero/Editora UnB/MCT-CNPQ, 1989. 285 p.

GAZOLLA, M. Agricultura familiar, segurança alimentar e políticas públicas: uma análise a partir da produção para autoconsumo no território do Alto Uruguai/RS. Porto Alegre (RS): Série PGDR/UFRGS (dissertação de mestrado), 2004. 287 f.

GRISA, C. A produção "pro gasto”: um estudo comparativo do autoconsumo no Rio Grande do Sul. Porto Alegre: Série PGDR/UFRGS (dissertação de mestrado), 2007. 200 f.

HERÉDIA, B.M.A. A morada da vida: trabalho familiar de pequenos produtores do Nordeste do Brasil. Rio de Janeiro: Paz e Terra, v. 7, 1979. 164 p. (Série Estudos sobre o Nordeste).

LEITE, S.P. Autoconsumo y sustentabilidad en la agricultura familiar: una aproximación a la experiencia Brasileña. In: BELIK, W. Políticas de seguridad alimentaría y nutrición en América Latina. São Paulo: Hucitec, 2004. p. 123-181.

LOVISOLO, H.R. Terra, trabalho e capital: produção familiar e acumulação. Campinas: Editora da UNICAMP, 1989. 231 p.

NIEDERLE, P.A. Mercantilização, estilos de agricultura e estratégias reprodutivas dos agricultores familiares de Salvador das Missões - RS. Porto Alegre (RS): Série PGDR/UFRGS (dissertação de mestrado), 2007. 218 f.

PEYRÉ TARTARUGA, I. O papel da produção para o autoconsumo na segurança alimentar das populações rurais: um pouco da diversidade da agricultura familiar. In: I Colóquio Agricultura Familiar e Desenvolvimento Rural. Porto Alegre (RS): PGDR/UFRGS, Cd-Roan, 23 p., 2005.

PROGRAMA DAS NAÇÕES UNIDAS PARA O DESENVOLVIMENTO et al. Atlas do desenvolvimento humano no Brasil, 2000. Disponível em: http://www.pnud.org.br/atlas. Acesso em: jun. 2006.

RADOMSKY, G.F.W. Redes sociais de reciprocidade e de trabalho: as bases histórico-sociais do desenvolvimento na Serra Gaúcha. Porto Alegre: PGDR/UFRGS (dissertação de mestrado), 2006. 205 f. 
SAHLINS, M. Sociedades tribais. Rio de Janeiro: Zahar, 1970. 178 p.

SCHNEIDER, S. et al. A pluriatividade e as condições de vida dos agricultores familiares do Rio Grande do Sul. In: SCHNEIDER, S. (Org.). A diversidade da agricultura familiar. Porto Alegre: Editora da UFRGS, 2006. p.137-164.

SEYFERTH, G. A colonização alemã no vale do Itajaí-mirim: um estudo de desenvolvimento econômico. Porto Alegre: Movimento, 1974. 159 p.

TAVARES DOS SANTOS, J.V. Colonos de vinho: estudo sobre a subordinação do trabalho camponês ao capital. 2. ed. São Paulo: Editora Hucitec, 1984. 182 p.

TEDESCO, J.C. Terra, trabalho e família: racionalidade produtiva e ethos camponês. Passo Fundo: EDIUPF, 1999. 331 p.

WAGNER, S.A.; MARQUES, F.C.; MENASCHE, R. Agricultura familiar à mesa. In: MENASCHE, R. (Org.). A agricultura familiar à mesa: saberes e práticas da alimentação no Vale do Taquari. Porto Alegre: Editora da UFRGS, 2007. p. 33-45.

WOLF, E. Sociedades camponesas. 2. ed. Rio de Janeiro: Zahar Editores, Curso de Antropologia Moderna, 1976. 147 p.

WOORTMANN, K. Hábitos e ideologias alimentares em grupos sociais de baixa renda: relatório final. Série antropologia. n. 20, 1978. 114 p. WOORTMANN, E.F.; WOORTMANN, K. O trabalho da terra: a lógica e a simbólica da lavoura camponesa. Brasília: Editora Universidade de Brasília, 1997. 192 p. 